\title{
A descentralização de recursos no financiamento da Educação Básica
}

\author{
Decentralization of resources in financing Basic Education
}

\begin{abstract}
Rosemary Roggero
Doutora em Educação. Pontifícia Universidade Católica de São Paulo - PUC.

São Paulo, SP - Brasil.

roseroggero@uol.com.br

Adriana Zanini da Silva

Doutoranda em Educação - Bolsista CAPES. Universidade Nove de Julho - UNINOVE.

São Paulo, SP - Brasil.

azaninidasilva@yahoo.com.br
\end{abstract}

Resumo: Este trabalho analisa a política de descentralização de recursos financeiros da educação básica. Situa a descentralização de recursos no contexto social, econômico e político; analisa a descentralização nos preceitos da Constituição Federal de 1988 e no Plano de Reforma do Estado Brasileiro; sua implementação na educação por meio das políticas de fundos, dos programas específicos do Fundo Nacional de Desenvolvimento da Educação, dos municípios pesquisados e seus impactos na gestão das escolas. Justifica-se pelo processo de disputa em que se encontra o financiamento da educação básica brasileira. A pesquisa empírica deu-se em escolas de educação básica de São Paulo e sua região metropolitana. Constata-se que a descentralização dos recursos financeiros não se efetiva como tal, mas como desconcentração.

Palavras-chave: Descentralização de recursos. Financiamento da educação. Fundeb. Gestão democrática. PDDE.

Abstract: This paper analyzes the policy of decentralization of financial resources of basic education. It situates the decentralization of resources in the social, economic and political context; analyzes the decentralization in the precepts of the Federal Constitution of 1988 and in the Plan of Reform of the Brazilian State; its implementation in education through the policies of funds, specific programs of the National Fund for Education Development, the municipalities surveyed and their impacts on the management of the schools. It is justified by the dispute process that is the financing of Brazilian basic education. The case study was carried out in schools of basic education of São Paulo and its metropolitan region. It is noted that the decentralization of financial resources is not effective as such, but as deconcentration.

Keywords: Decentralization of resources. Financing education. Fundeb. Democratic management. PDDE. 
Introdução

O financiamento da educação é um dos eixos fundamentais para o avanço social, econômico e político do país, pois é o disparador das políticas públicas de educação, responsáveis por impulsionar a diminuição das desigualdades educacionais e sociais. Estudos de Adrião (2017, 2007), Arretche (1996), Dalbor (2017), Harvey (2011, 2008), Pinto (2018) Vieira e Vidal (2015), dentre outros, ainda que diversos nos seus enfoques, permitem afirmar que desde a sua origem, o financiamento da educação brasileira tem estado atrelado aos interesses econômicos das classes hegemônicas e pouco avançou para a diminuição das desigualdades sociais, econômicas e educacionais, em relação ao próprio crescimento econômico, em qualquer período que se verifique. Entre esses estudos, Vieira e Vidal (2015) discutem que avançamos de uma política de indefinição de recursos para uma política de vinculação de recursos e, recentemente, para uma política de fundos específica para o ensino fundamental, seguida de uma política específica de fundos para a educação básica, ainda que esse processo tenha apenas amenizado e não superado o problema da desigualdade educacional brasileira. Essa estrutura revela que o financiamento da educação brasileira está em processo de configuração atravessada por interesses diversos, não raro antagônicos.

Em todo o mundo contemporâneo, a educação é vista, hoje, como um grande negócio, com vários nichos de mercado influenciados pela globalização e pelo neoliberalismo. Harvey (2008, p. 104), ao analisar as recentes transformações econômicas, culturais e suas influências na sociedade contemporânea, também destaca o papel do Estado como “[...] um segundo princípio organizador por meio do qual a classe dominante pode tentar impor sua vontade não somente aos seus oponentes, mas também ao fluxo, à mudança e à incerteza anárquicos a que a modernidade capitalista sempre está exposta". Nesse contexto, o neoliberalismo incentiva a diminuição da presença do Estado nos investimentos sociais por meio da contenção, da diminuição dos montantes de recursos investidos e, especialmente, do aumento da transferência de recursos ao setor privado. Em boa medida, essa postura coloca em risco a implementação do Plano Nacional de Educação, aprovado pela Lei $n^{\circ} 13.005$ de 2014, que prevê, na Meta 20, a ampliação do financiamento da educação para o atendimento às demandas de expansão do ensino com os padrões de qualidade.

Os autores contrários às políticas de arrocho fiscal com perda de investimentos na área social, como Harvey (2011), Dalbor (2017) e Piketty (2014), defendem que a alternativa para a diminuição das desigualdades educacionais é garantir os investimentos sociais e os direitos já conquistados, por meio do enfrentamento dos problemas que emperram o crescimento 
econômico, como: resgatar a dimensão pública do Estado, repensar a lógica do sistema tributário, reduzir as taxas de juros, reconverter as atividades especulativas para o fomento econômico, incentivar as políticas redistributivas e enfrentar a dívida pública ampliando, por exemplo, o processo de nacionalização dos setores bancário e industrial.

Nesse contexto em que o projeto de país e, dentro dele, o próprio financiamento da educação básica brasileira, encontra-se em disputa, a temática da descentralização de recursos na educação precisa ser repensada. No entanto, a análise legal e documental é insuficiente para a compreensão dos avanços e entraves, é preciso analisá-la à luz das práticas de gestão das escolas para que os impactos na qualidade da educação sejam compreendidos.

A descentralização na educação básica brasileira: o jogo obscuro da centralização de decisões

As mudanças contemporâneas do capitalismo induziram novas relações entre o Estado e a sociedade. $O$ aumento das transações financeiras que se deram em função da liberação, desregulação dos mercados e das atividades financeiras pelos governos, possibilitaram o aumento dos sistemas especulativos em detrimento dos produtivos: a financeirização. Esse novo modelo tem impactado a sociedade à medida que as especulações passam a render mais do que a produção, desmotivando os investimentos nas empresas e indústrias e, consequentemente, aumentando o desemprego, diminuindo os rendimentos salariais a ampliando as desigualdades sociais.

\footnotetext{
E a realidade fundamental é que a aplicação financeira rende mais do que o investimento produtivo. O PIB mundial cresce num ritmo situado entre $1 \%$ e $2,5 \%$ segundo os anos. As aplicações financeiras rendem acima de $5 \%$ e frequentemente muito mais. [...] a produtividade é esterilizada por um sistema generalizado de especulação que drena as capacidades de investir na economia real. (DOWBOR, 2018, p. 33)
}

Incentivada pelos países centrais, por meio de acordos com os organismos internacionais, a financeirização representa uma alteração na configuração do sistema capitalista que impacta nas relações do Estado com a sociedade. No Brasil, a adesão ao Consenso de Washington marca esse novo modelo de Estado que iniciou em meados da década de 1990, no governo Fernando Henrique Cardoso, com o Plano de Reforma do Estado e teve como fundamento a diminuição dos gastos público por meio das privatizações, das reformas na seguridade social e administrativa. Para Santos (1998, p. 08), o Consenso de Washington com suas metas, fruto de um capitalismo global, “[...] desestruturaram os espaços nacionais de conflito e negociação, minaram a capacidade financeira e reguladora do Estado.” 
Embora o Consenso de Washington não tenha sido completamente aceito pela sociedade brasileira, na educação, a adesão implementou vários debates influenciados, principalmente, pelos organismos internacionais, que têm como objetivo amparar os países periféricos no seu desenvolvimento econômico por meio da reestruturação produtiva e da reforma do Estado (LIMA, 2017, p.142.). Na educação, defendem a lógica da eficiência e da competição, estimulam a concorrência e a privatização, controlam a produção do conhecimento por meio das demandas dos setores produtivos, pressionam o sistema público a diminuir os gastos e direcionam a implementação de uma política compensatória para diminuir os conflitos, a tensão social e não as desigualdades. Têm contribuído para a regulação da política educacional brasileira e incidido, dentre outros, sobre os diagnósticos, a reorganização curricular, a gestão, a avaliação e o próprio financiamento da educação.

Neste contexto de mudanças do papel do Estado e da sociedade, foi aprovada a subvinculação de recursos na educação brasileira. Promulgada pela Emenda Constitucional no 14 , de 12 dezembro de 1996 (EC 14/96), que instituiu os fundos de natureza contábil ${ }^{1}$ e redistributiva, a princípio, o Fundo de Manutenção e Desenvolvimento do Ensino Fundamental e de Valorização do Magistério (FUNDEF) com vigência de 1997 a 2006 e, posteriormente, o Fundo de Manutenção e Desenvolvimento da Educação Básica e Valorização dos Profissionais da Educação (FUNDEB), com vigência de 2007 até o final de 2020, tornado constitucional a partir de 2021, por meio da aprovação da Emenda Constitucional no. 108, de 26 de agosto de 2020(EC108/2020).

A política de fundos induziu a descentralização da educação por meio da implementação da política de redistribuição de recursos financeiros entre os entes federados. O Fundef permitiu a universalização do ensino fundamental e o Fundeb permitiu mais avanços, por contemplar também a educação infantil, a educação de jovens e adultos e o ensino médio, estabeleceu o piso salarial nacional para os profissionais da educação e melhorou, em alguns casos, a redistribuição dos recursos entre os estados.

Os recursos dos fundos não tiveram aumentos significativos ao longo dos anos, a não ser acompanhando o desempenho econômico e a arrecadação tributária do país, e seu critério redistributivo dos recursos amenizou, mas não solucionou o problema da desigualdade educacional, apesar da complementação da União. Para Araújo (2016), o Fundeb redistribuiu impostos existentes, sem acrescentar recursos novos para o sistema educacional como um todo, a não ser a complementação da União para alguns estados e municípios. Para Pinto (2018) o Fundeb não garantiu recursos para o padrão mínimo de qualidade do ensino e limitou recursos, principalmente para a Creche e Educação de Jovens e Adultos, inviabilizando sua expansão. 
Observa-se que um dos principais problemas da aprovação das políticas de fundos foi a sobreposição das metas do Plano de Reforma do Estado às discussões acordadas no processo constituinte em 1987 e 1988, que ressignificou e alterou aspectos importantes na concepção de custos da educação, objeto de discussão acirrada durante o processo de elaboração da Constituição Federal de 1988 (CF/88) e que associava padrões mínimos de qualidade do ensino aos custos necessários à Manutenção e Desenvolvimento do Ensino (MDE). A sobreposição que priorizou as metas do Plano de Reforma de Estado iniciada pelo governo Fernando Henrique Cardoso, mantida nos governos Lula, Dilma e intensificada nos governos Temer e Bolsonaro, não contribuiu para resolver o problema das desigualdades educacionais, inviabilizou a implementação do Plano Nacional de Educação (PNE) e ainda pode colocar em risco a regulamentação da EC 108/2020 no que se refere à destinação dos novos recursos à educação infantil, exclusivamente, às escolas públicas e a implementação do Custo Aluno Qualidade (CAQ) que definirá os padrões de qualidade e poderá aprimorar a distribuição, a gestão e o controle social dos gastos.

Concomitante aos avanços e entraves da descentralização das políticas de fundos, observase a descentralização de recursos às escolas, por meio dos programas específicos do governo federal que exigem adesão dos municípios e entram na base de cálculo dos gastos com educação: o Programa Caminho da Escola, Programa de Aceleração do Crescimento, Programa Nacional do Livro Didático, Programa Dinheiro Direto na Escola (PDDE), dentre outros programas federais e específicos de cada rede de ensino, como por exemplo, o Programa de Transferência de Recursos Financeiros da Prefeitura de São Paulo (PTRF), o Programa Fundo Rotativo da Prefeitura de Curitiba e o Programa de Descentralização Administrativa e Financeira do Distrito Federal.

Os recursos que chegam às escolas através dos programas, sejam eles federal, estaduais ou municipais, têm destinação específica de acordo com a legislação que normatiza sua aplicação e são utilizados para despesas de custeio e de capital. As despesas de custeio destinam-se à contratação de serviços ou aquisição de materiais de consumo, aqueles que em razão de seu uso corrente perdem normalmente sua integridade física e/ou tem sua utilização limitada a dois anos, como por exemplo, o pagamento de mão de obra para pequenos consertos na rede elétrica, hidráulica, conserto de equipamentos, aquisição de material didático, material de escritório etc. A despesa de capital destina-se à aquisição de material permanente, aquele que em razão de seu uso corrente não perde a sua identidade física e/ou tem uma durabilidade superior a dois anos, como por exemplo, a aquisição de equipamentos eletroeletrônicos, carteiras escolares, fogões, quadro de giz etc.

Fica a cargo das Unidades Executoras, que representam os diferentes segmentos e são presididas pelos diretores e diretoras das unidades escolares, a definição de como serão gastos os 
recursos descentralizados; no entanto, os atrasos na liberação dos valores, o prazo curto para a execução, o excesso de burocracia e até mesmo o descompromisso com a gestão democrática têm prejudicado o processo coletivo de tomada de decisão. Além disso, os recursos com destinação específica nem sempre atendem as necessidades pedagógicas, o que coloca a comunidade escolar como mera executora dos programas planejados pelos órgãos centrais.

A descentralização também se realiza por meio da transferência de recursos ao setor privado. No caso da educação, o setor privado passou a gerenciar, dentre outras coisas, a formação dos professores, a organização curricular, a gestão das escolas e cada vez mais, requerer parte do dinheiro da educação por meio de incentivos, subvenções fiscais, convênios, bolsas de estudo e subsídios. Adrião e Peroni em um estudo sobre o PDDE, em escolas de diferentes regiões do Brasil, destacam estratégias implícitas da descentralização da década de 1990:

A nova retórica de descentralização que pretende estimular a participação da sociedade na esfera política tem como finalidade aproximação entre financiamento e administração, tanto nas relações do poder público com o mercado, quanto na transferência de responsabilidade para os municípios e para a escola, no caso da educação. Assim, pode se justificar a restrição do financiamento público para a educação, alegando-se que os problemas educacionais não decorrem da falta de recursos, mas da falta de uma melhor administração desses recursos. (ADRIÃO e PERONI, 2007, p.49).

Segundo Bianchetti (1997), a descentralização poderia ser considerada uma estratégia para fortalecer e consolidar a democracia por meio da influência de diferentes sujeitos no planejamento, nas tomadas de decisão e no controle das políticas, garantindo autonomia às bases e mudanças nas relações de poder, inclusive nas escolas. Esta compreensão valoriza a participação de todos os sujeitos nos processos decisórios, defende o fortalecimento das instâncias locais, a participação de diferentes atores no planejamento, na implementação e na avaliação das políticas públicas, sendo uma possibilidade para o fortalecimento de ações democráticas.

Gadotti (1994) e Arretche (1996) chamam a atenção para o fato de que a descentralização vai da simples transferência de competências a uma complexa reestruturação do poder decisório, por isso, são as opções políticas e ideológicas que definem a dimensão que a descentralização assumirá, o que revela a importância de compreender a finalidade a que se propõem e sua dinâmica de execução e acompanhamento, ou seja, é preciso pensar no modo como se faz a gestão desse processo.

Por esse motivo, a defesa e a adoção da descentralização estão presentes tanto em discursos de progressistas, quanto de conservadores - todos eles presentes e disputando, de algum modo, no jogo democrático. Teoricamente, a descentralização pode ser assumida como um componente do estado mínimo para os conservadores liberais, enquanto para os progressistas social democratas 
uma forma de incentivo à autonomia das escolas, da participação dos cidadãos e da redefinição das relações de poder nas diferentes instâncias. Mas o jogo não é tão simples, sob o capitalismo.

Seja do ponto de vista conservador ou progressista, Castro e Lauande (2009) problematizam as relações entre a descentralização e as relações de trabalho, pois a globalização e a internacionalização da economia transformaram não só as estruturas do sistema capitalista, como as estruturas do Estado. As novas relações de trabalho que se estabeleceram na sociedade contemporânea, pautadas na flexibilização, terceirização e crescimento da informalidade ocasionaram mudanças na arrecadação de impostos e revelaram que o Estado descentralizado tem sido, cada vez mais, determinado pelo capital e a descentralização a favor da reprodução do capital e das novas relações de trabalho, cujo objetivo principal é o controle de gastos sociais e a não regulação econômica por parte do Estado.

Com o intuito de analisar em que medida os recursos financeiros descentralizados interferem no planejamento, na implementação e na organização do trabalho pedagógico, Paro (2011) indica a importância de atentar para a organização de todo o trabalho na escola, principalmente na distribuição de autoridade e de poder. Para o autor, a compreensão das relações de autoridade e de poder nos processos descentralizados exige analisar os diferentes diálogos que se estabelecem e o que prevalece nas mobilizações, nas negociações e nas tomadas de decisões, bem como as mudanças na rotina escolar, nos currículos, na organização dos tempos e dos espaços, e, principalmente, nos processos de ensino, o que revela a construção de processos democráticos ou autoritários na escola.

Assim, pode-se observar que a consolidação dos ideais democráticos nas ações descentralizadas depende da natureza das instituições. (ARRETCHE, 1996). No Brasil, destaca-se que os conteúdos atribuídos à descentralização assumidos pelas políticas reformistas da década de 1990, diferenciaram-se dos conteúdos das lutas políticas dos anos 1980, pois a CF/88 incorporou o discurso da descentralização com base nos princípios da redemocratização da década de 1980, porém, efetivou-se na recontextualização do papel do Estado, nos anos 1990, nos eixos da Nova Gestão Pública (NGP), que adotou os princípios da gestão privada na gestão pública. (OLIVEIRA, 2015).

Esse modelo esvazia o significado político da participação, escamoteia a desresponsabilização do Estado com as políticas sociais, valoriza a implementação da lógica privada, o foco em resultados, o planejamento e monitoramento central pela União. No caso da educação, tende a uma visão reducionista das escolas e impacta as decisões sobre seu financiamento. Entendido como neoliberal, propõe que a superação da crise do Estado só seja 
possível mediante a diminuição da sua atuação nas áreas consideradas geradoras de déficit público - as sociais - por meio do processo de privatização e mercantilização.

Harvey (2011), ao analisar o Estado neoliberal em várias partes do mundo, permite ampliar a compreensão das características da descentralização no Brasil contemporâneo. Ao considerar que as políticas de descentralização podem ampliar o controle centralizador, estas acabam assumindo o caráter de desconcentração pela subordinação hierárquica e decisória em relação ao órgão central. A desconcentração mantém o planejamento das políticas, com o aparato técnico-científico no poder central e descentraliza, apenas, sua operacionalização e prestação de contas. Nesse contexto, a mera descentralização de recursos financeiros pode favorecer os órgãos centrais em detrimento das demandas das escolas, como observado no cotidiano escolar.

\section{A descentralização de recursos financeiros no cotidiano das escolas de educação básica}

A pesquisa empírica buscou compreender como se dá o uso dos recursos públicos descentralizados, recebidos pelas escolas e utilizados por elas, com base nos planos de gestão ou nos Projetos Político-Pedagógicos que constroem e implementam, em acordo com a equipe escolar e com as comunidades, por meio dos conselhos de escola. Permitiu o levantamento de dados em 21 escolas de educação infantil, ensino fundamental e médio das redes municipal e estadual de São Paulo, por meio de entrevistas com gestores e levantamento de documentos fiscais e contábeis das mesmas que revelam um panorama da realidade da Educação, particularmente na Cidade de São Paulo e sua região metropolitana.

De modo geral, quando se trata do tema financiamento da educação e descentralização, não há discussões e acompanhamento pelas escolas sobre os gastos do Fundeb, apesar dos Conselhos de Acompanhamento instituído em cada município. Os gestores das escolas destacaram a descentralização de recursos financeiros, com ênfase ao PDDE e aos programas específicos de cada município, pelo fato destes serem os recursos que podem ser discutidos e utilizados a partir das demandas dos Projetos Políticos-Pedagógicos, apesar da burocracia que os cercam, principalmente em relação aos prazos de execução, formas de gastos permitidos e prestação de contas que nem sempre coadunam com os tempos escolares.

Segundo o Fundo Nacional para o Desenvolvimento da Educação (FNDE), o PDDE tem por objetivo prover de forma suplementar as escolas com recursos financeiros, visando à melhoria da infraestrutura física e pedagógica sem intermediários; incentiva a autonomia gerencial, a participação da comunidade escolar e o atendimento das necessidades locais. 
Os recursos do programa advêm, em sua maior parte, do salário-educação ${ }^{2}$ e os repasses levam em conta as desigualdades regionais; por esse motivo, as regiões Norte, Nordeste e Centro Oeste recebem valores maiores que as regiões Sul e Sudeste, variando, por exemplo, de R \$33,24 por aluno, recebi por Arari, no Maranhão, a R \$23,32 por aluno, recebido pela Prefeitura de São Paulo, no ano de 2018.

É possível observar que muitos dos gastos são centralizados no governo federal, como a compra de livros didáticos, programa de alimentação escolar, apoio ao transporte escolar, informática na educação, dentre outros, e nas Secretarias de Educação, desde a construção e reformas das escolas, passando pela compra de material escolar, livros, brinquedos e mesmo o transporte escolar oferecido em determinadas circunstâncias, chegando ao pagamento de pessoal próprio ou terceirizado. Os recursos que chegam às escolas são voltados a pequenos gastos e pequenas manutenções e projetos. Apesar disso, na totalidade das escolas pesquisadas, foram observadas queixas sobre excesso de burocracia, regulamentação legal e apoio técnico centralizado, seja do governo federal, estadual ou municipal, conforme o projeto, prazos apertados para gastar e prestar contas dos recursos, inadequação da destinação dos valores em relação às necessidades e descompasso entre os recursos locais disponíveis e as responsabilidades.

Por outro lado, nota-se uma dificuldade, no âmbito das escolas, em relação ao planejamento, utilização e controle de gastos com a participação dos conselhos de escola, o que costuma ser escamoteado, quando os recursos são devolvidos para evitar a burocracia na prestação de contas, o que permite constatar a frágil preparação dos gestores para lidar com os processos e trâmites necessários. Recursos recebidos por meio de compra centralizada, muitas vezes não são valorizados ou utilizados: livros didáticos e material escolar, não raro sequer chegam a ter pacotes abertos e são descartados, muitas vezes, sob a justificativa de que não correspondem às necessidades das escolas. O comprado nem sempre é o solicitado.

Pode ser observado que as escolas se veem com dificuldades na aplicação dos recursos, porque não entendem a lógica que a regulamenta, faltando formação específica aos gestores, no que se refere, inclusive, a buscar adequar a relação entre os tempos da distribuição, chegada dos recursos e os tempos escolares com seus Projetos Político-Pedagógicos, bem como pela falta de discussão e implementação dos padrões mínimos de qualidade.

As experiências também revelam significativas diferenças na compreensão e nas práticas, incluindo fortes contradições em relação ao que se entende por gestão democrática, o que em alguns casos, posterga a participação de toda a comunidade escolar na decisão do uso dos recursos. Aos supostos avanços em relação ao financiamento, em sua especificidade, na descentralização de 
recursos financeiros, não corresponderam práticas efetivamente inclusivas, participativas e democráticas. Os conselhos municipais e estaduais de educação não têm sido eficientes neste acompanhamento e orientações, até porque se mantêm muito distantes da realidade das escolas, funcionando não raro, como órgãos sem grande representatividade junto às suas comunidades. A participação ainda tende a ser restrita e a decisão centralizada, inclusive pelas escolas, o que confirma os estudos de Gadotti (1994) e Arretche (1996) de que a descentralização pode adotar o caráter de transferência de responsabilidades sem incidir sobre a democratização dos poderes decisórios, mantendo o caráter centralizador e de subordinação hierárquica, destacado por Harvey (2011).

Por outro lado, uma formação específica e competente para os gestores escolares, por parte dos órgãos centrais das secretarias, a respeito do investimento, dos fundamentos legais e procedimentais do planejamento, da disponibilização de recursos e da prestação de contas, é imperiosa. É fundamental também, discutir a relação entre os recursos recebidos pelas escolas, processos participativos e o objetivo de garantia do padrão mínimo de qualidade, pensados em cada Plano Estadual e Municipal de Educação, bem como nos Projetos Político Pedagógicos de cada unidade escolar, considerando a articulação com as políticas de recursos humanos, de compras e de prestação de contas. Também é preciso considerar a formação dos gestores para dar conta dos processos. Sem essa articulação vive-se a crítica de que os recursos financeiros descentralizados estão descontextualizados das necessidades reais, o que impõem a necessidade de rever o seu uso e o cumprimento dos objetivos a que se destinam.

Esse cenário de contradições, caracteriza-se como desconcentração, assumida equivocadamente nos discursos políticos como descentralização. A desconcentração contribui para que os recursos do PDDE e do PTRF nas escolas assumam a mesma lógica dos governos centrais: o uso sem a estreita relação com os insumos necessários à qualidade da educação. Nesse sentido, fica patente o significado da desresponsabilização do governo central e a responsabilização dos dirigentes escolares.

\section{Considerações finais}

As experiências aqui analisadas demonstram, em certa medida, que o financiamento da educação brasileira está em processo de configuração, é permeado por disputas de interesses diversos e ainda não garante a igualdade de oportunidades educacionais. Apesar das contradições do processo de descentralização de recursos, observa-se avanços, principalmente com o Fundeb, 
que se tornou o principal instrumento da política de financiamento da educação básica nas últimas décadas e amenizou as desigualdades educacionais.

No entanto, nos processos de descentralização, tem havido a predominância de procedimentos técnicos, operacionais e gerenciais, ficando em segundo plano a dimensão política, própria dos processos coletivos de autonomia, tomada de decisão e melhoria da qualidade da educação, ainda que os mecanismos para tal estejam presentes na legislação, o que revela a imaturidade da nossa democracia, também no interior das escolas, logo, a aprovação de um Fundeb permanente, constitucionalmente garantido e com uma complementação robusta de recursos por parte da União é fundamental, assim como, rever a centralização das decisões nos programas descentralizados às escolas para que tenham mais autonomia na implementação dos seus Projetos Político Pedagógicos.

A descentralização normatizada e implementada pelas políticas de financiamento da educação básica por meio dos fundos, dos programas diversos do governo federal e dos recursos descentralizados pelos municípios pesquisados, tem assumido o caráter de desconcentração, pois acrescenta pouco dinheiro às escolas enquanto mantém centralizado o poder de decisão nos órgãos centrais; além disso, não relaciona aos insumos necessários à garantia da qualidade.

A pesquisa tem apontado para a necessidade de informação mais direta e objetiva sobre os recursos destinados à educação e como é definida sua utilização, a que entraves estão sujeitos, quais os determinantes legais para o uso e os limites para cada rubrica de despesas. Defendemos, portanto, o orçamento participativo da educação e o acompanhamento dos gastos com maior comunicação e transparência para toda a sociedade, se queremos sair dos jogos de discurso de culpabilização que funcionam como cortina de fumaça para o que não funciona e não se quer ver: as contradições de uma sociedade capitalista, minada por jogos de poder e de manutenção da minoridade social de seus cidadãos.

Nessa direção, a escola continua sendo palco de disputas - as visíveis, no complexo e conflituoso cotidiano escolar, e as camufladas por interesses de outras camadas da sociedade, tecidas nos vãos da burocracia estatal. Entretanto, tendo em vista a escolha da sociedade brasileira, neste momento histórico, por um projeto tido como conservador é preciso observar acuradamente as propostas das políticas de financiamento para a melhoria da qualidade da educação, sob a Constituição Federal de 1988, a constituição democrática.

\footnotetext{
${ }^{1}$ Constitui fundo de natureza contábil ou financeira, a modalidade de gestão de parcela de recursos do Tesouro Nacional, vinculados por lei à realização de determinados objetivos de política econômica, social ou administrativa do Governo.
} 


\section{Dialogia}

ROGGERO, Rosemary; SILVA, Adriana Zanini da. A descentralização de recursos no financiamento da Educação Básica

${ }^{2}$ O Salário-Educação é uma contribuição social recolhida pelas empresas, destinada ao financiamento de programas, projetos e
ações voltados para a educação básica pública, conforme previsto no $₫ 5^{\circ}$ do art. 212 da Constituição Federal de 1988.

\section{Referências}

ADRIÃO, Theresa e PERONI, Vera Maria Vidal. Programa Dinheiro Direto na Escola: Uma proposta de redefinição do Estado na educaşão? Brasília: Instituto Nacional de Estudos e Pesquisas Educacionais Anísio Teixeira, 2007. 204 p.

ARAÚJO, Luiz. O CAQi e o novo papel da União no financiamento da Educação Básica. Jundiaí: Paco Editorial. 2016.

ARRETCHE, Marta Teresa da Silva. O Mito da Descentralização: Maior Democratização e Eficiência das Políticas Públicas? Revista Brasileira de Ciências Sociais, ANPOCS, n.31, 1996.

BIANCHETT, R. G. O modelo neoliberal e as políticas educacionais. São Paulo: Editora Cortez, 1997.

BOBBIO, Norberto et all. Dicionário de Política. $2^{a}$ ed. Brasília: Universidade de Brasília, 1986. 459 p.

BRASIL. Lei Federal no 13.005 de 25 de junho de 2014. Aprova o Plano Nacional de Educação -PNE e dá outras providências. Disponível em http://www.planalto.gov.br/.

BRASIL. Emenda Constitucional 108, de 26 de agosto de 2020. Dispõem sobre o Fundo de Manutenção e Desenvolvimento da Educação Básica e de Valorização dos Profissionais da Educação (Fundeb); altera o Ato das Disposições Constitucionais Transitórias; e dá outras providências. Diário oficial da União, Brasília, DF, 27 de agosto de 2020. Seção 1, p.5.

BRASIL. Constituição 1998. Emenda Constitucional n.14, de 12 de setembro de 1996. Modifica os artigos. 34, 208, 211 e 212 da Constituição Federal e dá nova redação ao art. 60 do Ato das Disposições Constitucionais Transitórias. Diário Oficial da União, Brasília, DF, 13 de set. de 1996. Seção 1, p. 18109.

BRASIL. Lei Federal n 11.494, de 20 de junho de 2007. Regulamenta o Fundo de Manutenção e Desenvolvimento da Educação Básica e de Valorização dos Profissionais da Educação - Fundeb. Diário Oficial da União, Brasília, DF, 21 jun. 2007, Seção 1, p.7.

BRASIL. Lei Federal n ${ }^{\circ}$ 9.424, de 24 de dezembro de 1996. Dispõe sobre o Fundo de Manutenção e Desenvolvimento do Ensino Fundamental e de Valorização do Magistério FUNDEF. Diário oficial da União, Brasília, DF, 26 dez. 1996.

BRASIL. Constituição da República Federativa do Brasil de 1988. Presidência da República. Disponível em: http://www.planalto.gov.br/. Acessado: 20, jan. 2019.

BRASIL. Fundo Nacional de Desenvolvimento da Educação - FNDE. Programa Dinheiro Direto na Escola-PDDE. Disponível em: https://www.fnde.gov.br/programas/pdde. Acessado: 23, jan. 2019

CASTRO, Alda Maria Duarte Araújo e LAUANDE, Maria de Fátima Ribeiro Franco. A descentralização como componente da gestão educacional. Cadernos ANPAE, v.8, p.345-358, 2009. 
DOWBOR, Ladislau. A era do capital improdutivo: Por que oito famílias têm mais riqueza do que a metade da população do mundo? São Paulo: Autonomia Literária, 2017.

GADOTTI, M. Pressupostos do projeto pedagógico. In: MEC: Conferência Nacional de Educação para Todos. Brasília: DF, 1994.

HARVEY, David. O enigma do capital e as crises do capitalismo. 1a ed. São Paulo: Boitempo, 2011.

HARVEY, David. A condição pós-moderna. 17ª ed. São Paulo: Edições Loyola, 2008.

OLIVEIRA, Dalila. Nova gestão pública e governos democrático-populares: contradições entre a busca da eficiência e a ampliação do direito à educação. Revista Educação \& Sociedade, Campinas, v. 36, no. 132, p. 625-646, jul.-set., 2015

PARO, Vitor Henrique. Crítica da estrutura da escola. São Paulo: Cortez, 2011. 248p.

PIKETTY, Thomas. O capital no século XXI. Tradução de Monica Baumgarten de Bolle. $1^{\mathrm{a}}$ ed. Rio de Janeiro: Intrínseca, 2014.

PINTO, José Marcelino de Rezende. O financiamento da educação na Constituição Federal de 1988: 30 anos de mobilização social. Revista Educação \& Sociedade, Campinas, vol. 39, n. 145, p. 846-869, nov. 14, 2018.

REZENDE, Flávio da Cunha. Rãões da crise de implementação do estado gerencial: Desempenho versus Ajuste fiscal. Revista Sociologia Política, Curitiba, 19, p 111-121, nov. 2002.

SANTOS, Boaventura de Sousa. A reinvenção solidária e participativa do Estado. Coimbra: Faculdade de Economia da Universidade de Coimbra, Centro de Estudos Sociais. 1988

VIEIRA, Sofia Lerche; VIDAL, Eloísa Maia. Política de Financiamento da educação no Brasil: uma (re)construção histórica. Revista Em Aberto, Brasília, v. 29, n. 93, p. 14-42, jan./jun. 2015.

Recebido em: 14 set. 2020/ Aprovado em: 13 nov. 2020

Cite como

(ABNT NBR 6023:2018)

ROGGERO, Rosemary; SILVA, Adriana Zanini da. A descentralização de recursos no financiamento da Educação Básica. Dialogia, São Paulo, n. 36, p. 568-580, set./dez. 2020. Disponível em: https://doi.org/10.5585/dialogia.n36.18175.

American Psychological Association (APA)

Roggero, R.; \& Silva, A. Z. (2020, set./dez.). A descentralização de recursos no financiamento da Educação Básica. Dialogia, São Paulo, 36, p. 568-580. https://doi.org/10.5585/dialogia.n36.18175. 